\title{
DIREITO À TERRA COMO UM DIREITO DA PERSONALIDADE INDÍGENA: O ESTUDO DE CASO DO CONFLITO DE TERRAS DA TRIBO GUARANI-KAIOWÁ
}

Maria Vital da Rocha*

Álisson José Maia Melo**

SUMÁRIO: Introdução; 1.1 Entre o jusnaturalismo e o positivismo jurídico: uma tentativa de conciliação nos direitos da personalidade; 2 Direito à terra como um direito à identidade do indígena; 2.10 direito à identidade como direito da personalidade e seus espectros de realização; 2.20 direito à terra como um elemento identitário indígena; 30 conflito entre o direito à terra como direito da personalidade e o direito de propriedade como direito real; 4 Conclusão; Referências.

RESUMO: Investiga-se a possibilidade de exame do conflito fundiário indígena sob o ponto de vista do direito civil, a partir da consideração da relação do índio com sua terra como um direito da personalidade. Com base no método dedutivo e pesquisa exploratória ancorada em dados secundários derivados de notícias de jornal e de material bibliográfico, parte-se de um modelo geral de direitos da personalidade, que tenta conciliar o jusnaturalismo com o positivismo jurídico para, em seguida, se analisarem o aspecto identitário da relação do índio com a terra e como teria repercussões nos direitos da personalidade. Reconhecendo-se o direito à terra como um direito à identidade indígena e, portanto, um direito da personalidade, e diagnosticado o impasse dado pelo direito constitucional, intenta-se solucionar o conflito fundiário e a antinomia normativa sob a ótica do direito civil. Ao final, conclui-se pela proteção dos direitos da personalidade dos indígenas, garantindose-lhes a posse das terras tradicionalmente ocupadas pelos povos originários, e aos proprietários de terras caberia o direito à indenização justa, prévia e em dinheiro a ser paga pela União.

PALAVRAS-CHAVE: Conflito fundiário; Direito à identidade; Direito à terra indígena; Etnia Guarani-Kaiowá.

Doutora em Direito Civil, pela Universidade de São Paulo (USP); Docente do Programa de Pós-graduação em Direito da Universidade Federal do Ceará (UFC). Coordenadora do Curso de Graduação e Docente do Programa de Pós-graduação em Direito do Centro Universitário 7 de Setembro (UNI7), Brasil.

** Doutorando em Direito pelo Programa de Pós-graduação em Direito da Universidade Federal do Ceará (PPGD/ UFC). Docente do Centro Universitário 7 de Setembro (UNI7), Brasil. E-mal: alisson.melo@gmail.com 


\section{THE RIGHT TO LAND AS A RIGHT OF THE INDIGENE PERSONALITY: A CASE STUDY ON THE GUARANI-KAIOWÁ'S LAND CONFLICTS}

ABSTRACT: The possibility of indigene land dispute is investigated from the point of view of Civil Law, or rather, the relationship between the indigene and the land as a right of personality. Current deductive and exploratory research, based on secondary data retrieved from newspapers and other bibliographic material, deals with an overall model of personality rights and conciliates the jus naturalis with judicial positivism. The identity aspect of the indigene-land relationship and its repercussions on personal rights are analyzed. The right to land is acknowledged as a right of indigene identity and, therefore, a right of the person. After diagnosing the stalemate provided by Constitutional Law, a solution between land disputes and the normative antinomy from the point of view of Civil Law is discussed. Results show that the rights of indigene personality should be protected, warranting a right to land traditionally occupied by their ancestors. Landowners should be indemnified justly and in cash by the State.

KEY WORDS: Land disputes; Right to identity; Right to indigene land; GuaraniKaiowá ethnicity.

\section{DERECHO A LA TIERRA COMO UN DERECHO DE LA PERSONALIDAD INDÍGENA: EL ESTUDIO DE CASO DEL CONFLICTO DE TIERRAS DE LA TRIBU GUARANÍ-KAIOWÁ}

RESUMEN: Se investiga la posibilidad de examen del conflicto de tierra indígena bajo el punto de vista del Derecho Civil, a partir de la consideración de la relación del indígena con su tierra como un derecho de la personalidad. Con base en el método deductivo e investigación exploratoria basada en datos secundarios derivados de noticias de periódicos y de material bibliográfico, se parte de un modelo general de derechos de la personalidad, que intenta conciliar el jusnaturalismo con el positivismo jurídico para, después, analizarse el aspecto de identidad de la relación del indígena con la tierra y como tendría repercusiones en los derechos de la personalidad. Reconociéndose el derecho a la tierra como un derecho a la identidad indígena y, por lo tanto, un derecho de la personalidad, y diagnosticado el estancamiento dado por el Derecho Constitucional, se intenta solucionar el conflicto de la tierra y la antinomia normativa bajo la óptica del Derecho Civil. Al final, se concluye por la protección de los derechos de la personalidad de los indígenas, garantiéndoseles la pose de las tierras tradicionalmente ocupadas por los pueblos originarios, y a los propietarios de tierras cabría el derecho a la compensación justa, previa y en dinero a ser pagada por la Unión.

PALABRAS CLAVE: Conflicto de la tierra; Derecho a la identidad; Derecho a la tierra indígena; Etnia Guaraní-Kaiowá. 


\section{INTRODUÇÃO}

É um lugar comum na história brasileira que, desde o descobrimento da Ilha de Vera Cruz, formalmente a partir do ano de 1500, as tribos indígenas vêm sendo dizimadas, colonizadas e marginalizadas em sua própria terra de origem. De um lado, a cultura colonizadora europeia avançou continuamente com sua tecnologia para desbravar as regióes do Novo Mundo e ali constituir vilas para fixação do homem branco na região e promoção do povoamento das vastas terras sem títulos de propriedade. De outro lado, as tribos indígenas foram sendo paulatinamente convertidas e subjugadas pelos colonizadores europeus, por meio da catequização, quando não assassinadas ou forçadas a migrar das áreas onde desenvolviam seu sistema comunitário de sobrevivência para regióes cada vez mais distantes.

Em vista disso, a Constituição da República Federativa do Brasil de $1988^{03}$ tenta devolver às tribos indígenas, ou o que restou delas, a dignidade que lhes foi tolhida ao longo desses quase 500 anos de perseguição e genocídio praticados pelo processo civilizatório de matriz europeia. Ela vai reconhecer, no art. 231, além de uma competência própria para organização social, os direitos originários sobre as terras que tradicionalmente ocupam. Os parágrafos desse dispositivo vão estabelecer regras especiais em torno do trato da terra.

Art. 231. São reconhecidos aos índios [...] os direitos originários sobre as terras que tradicionalmente ocupam, competindo à União demarcá-las, proteger e fazer respeitar todos os seus bens.

$\S 1^{\circ}$ São terras tradicionalmente ocupadas pelos índios as por eles habitadas em caráter permanente, as utilizadas para suas atividades produtivas, as imprescindíveis à preservação dos recursos ambientais necessários a seu bem-estar e as necessárias a sua reprodução física e cultural, segundo seus usos, costumes e tradições.

$\S 2^{\circ}$ As terras tradicionalmente ocupadas pelos índios destinamse a sua posse permanente, cabendo-lhes o usufruto exclusivo das riquezas do solo, dos rios e dos lagos nelas existentes.

$\S 3^{\circ} \mathrm{O}$ aproveitamento dos recursos hídricos, incluídos os potenciais energéticos, a pesquisa e a lavra das riquezas minerais em terras indígenas só podem ser efetivados com autorização do Congresso Nacional, ouvidas as comunidades

${ }^{03}$ BRASIL. Constituição (1988). Constituição da República Federativa do Brasil de 1988. Brasília, DF: Assembleia Nacional Constituinte, 1988. Disponível em: < http://www.planalto.gov.br/ > Acesso em: 15 ago. 2016. 
afetadas, ficando-lhes assegurada participação nos resultados da lavra, na forma da lei.

$\S 4^{\circ}$ As terras de que trata este artigo são inalienáveis e indisponíveis, e os direitos sobre elas, imprescritíveis.

$\S 5^{\circ}$ É vedada a remoção dos grupos indígenas de suas terras, salvo, "ad referendum" do Congresso Nacional, em caso de catástrofe ou epidemia que ponha em risco sua população, ou no interesse da soberania do País, após deliberação do Congresso Nacional, garantido, em qualquer hipótese, o retorno imediato logo que cesse o risco.

$\S 6^{\circ}$ São nulos e extintos, não produzindo efeitos jurídicos, os atos que tenham por objeto a ocupação, o domínio e a posse das terras a que se refere este artigo, ou a exploração das riquezas naturais do solo, dos rios e dos lagos nelas existentes, ressalvado relevante interesse público da União, segundo o que dispuser lei complementar, não gerando a nulidade e a extinção direito a indenização ou a ações contra a União, salvo, na forma da lei, quanto às benfeitorias derivadas da ocupação de boa fé.

$\S 7^{\circ}$ Não se aplica às terras indígenas o disposto no art. 174 , $\S 3^{\circ} \mathrm{e} \S 4^{\mathrm{o}}$.

Verifica-se, pelo exame dos parágrafos do art. 231, que a preocupação do constituinte com o tratamento das terras tradicionalmente ocupadas pelos indígenas denuncia a importância das terras para os povos indígenas. Marco fundamental na interpretação desse dispositivo constitucional é o julgamento do Supremo Tribunal Federal $^{04}$ na petição 3.388 / RR (Augusto Affonso Botelho Neto versus União), mais conhecido como o Caso Raposa Serra do Sol, terra indígena no Estado de Roraima, localizada nos confins da Região Norte brasileira. Entre diversas questões suscitadas, dignos de nota são os tópicos relativos à consideração do art. 231 da Constituição como capítulo avançado do constitucionalismo fraternal, em compensação pelas desvantagens historicamente acumuladas, e aos marcos temporais e circunstanciais de consideração para efeitos de terras tradicionalmente ocupadas, que seriam a partir da promulgação da Constituição, em 5 de outubro de 1988, condicionada a ocupação das terras à ostentação do caráter de perdurabilidade - para efeitos de estabilização das expectativas indígenas -, abrangendo inclusive os lugares onde, na data da promulgação da Constituição, aconteciam esbulhos pelos produtores rurais,

\footnotetext{
${ }^{04}$ BRASIL. Supremo Tribunal Federal. Tribunal Pleno. Petição 3.388 / RR. Relator Ministro Carlos Britto. Julgado em: 19 mar. 2009. Brasília, DF: STF, 2009. Disponível em: <http://stf.jus.br/> . Acesso em: 25 ago. 2016.
} 
constatados pela resistência e ânimo de ocupação indígena.

Sem prejuízo da evolução do processo de reconhecimento e devolução da dignidade dos povos indígenas por meio das terras após o advento da Constituição de 1988, tribos indígenas continuam a sofrer no Brasil duros ataques contra a proteção fundiária. Em especial, conseguiu chamar a atenção dos meios de comunicação internacionais a situação da etnia Guarani-Kaiowá na região longínqua do Estado do Mato Grosso do Sul, já na fronteira com o Paraguai.

Além de uma história sangrenta que remonta a registros em meados do século $\mathrm{XX}$, os conflitos permanecem até hoje causando baixas, especialmente para os indígenas, vítimas de reações desproporcionais. No caso dos indígenas GuaraniKaiowá, foi registrada uma carta pública, assinada pelos líderes das tribos indígenas, que prenuncia a morte coletiva dos índios na região com o avanço dos conflitos fundiários em virtude de ordem de despejo dada pela Justiça Federal em Mato Grosso do Sul ${ }^{05}$. Ao lado dos assassinatos decorrentes do conflito, tem-se registrado ainda um crescimento agressivo nas taxas de suicídio entre os índios GuaraniKaiowá, especialmente entre os jovens, alcançando 12 vezes a média geral nacional e o dobro da média indígena ${ }^{06}$.

A principal causa apontada para os suicídios se dá pela falta de perspectiva ocasionada pelo conflito fundiário estabelecido na região. Com o choque de realidades culturais, ocasionadas pelo processo civilizatório, e a expulsão dos índios de suas terras tradicionalmente ocupadas, os índios perdem sua referência oriunda dos laços tradicionais com a terra, aliada ainda à influência da cultura civilizatória no processo de globalização e à fragmentação dos núcleos familiares tribais ${ }^{07}$. Todos esses fatores, associados, já foram conduzidos para investigação pela Comissão Interamericana de Direitos Humanos, em virtude da omissão sistêmica do Governo Federal em resolver os conflitos na regiã $0^{08}$.

Os suicídios praticados nessas tribos, ocasionados pela perda de referência, despertam a atenção sob o ponto de vista dos direitos da personalidade. O presente estudo propõe-se a analisar a questão fundiária das tribos indígenas da etnia

${ }^{05}$ CARNEIRO, Júlia Dias. Carta sobre ,morte coletiva' de índios gera comoção e incerteza. BBC Brasil, Rio de Janeiro, 24 out. 2012. Disponível em: < http://www.bbc.com/> . Acesso em: 15 ago. 2016.

${ }^{06}$ LYONS, Charles. Suicides spread through a Brazilian tribe. The New York Times, New York, Sunday Review, Opinion, 2 jan. 2015. Disponível em: < http://www.nytimes.com/> Acesso em: 15 ago. 2016.

${ }^{07}$ UNTV. Suicide and despair among Brazil's indigenous. 21 ${ }^{\text {st }}$ Century Series, Programme \#97, 22 dec. 2014, 08:54. Disponível em: < http://www.unmultimedia.org/> Acesso em: 15 ago. 2016.

${ }^{08}$ FELLET, João. Brasil é cobrado na OEA por violência contra índios. BBC Brasil, São Paulo, 20 out. 2015. Disponível em: < http://www.bbc.com/> . Acesso em: 15 ago. 2016. 
Guarani-Kaiowá sob o ponto de vista dos direitos da personalidade, com um duplo propósito: primeiramente, identificar a existência de um direito à terra como um tipo especial de direito da personalidade, próprio do indígena, para, num segundo momento, confrontar os direitos civis oriundos da tutela da personalidade, pelo índio, e da tutela da propriedade, pelo setor agropecuário, para buscar uma solução à antinomia. As hipóteses iniciais da pesquisa são a de que o direito à terra indígena pode ser considerado sob o ponto de vista dos direitos da personalidade, um tipo especial derivado do direito à identidade pessoal, e a de que, no confronto entre o direito à terra, como direito da personalidade, e o direito à propriedade, como direito real, eventual indenização deve ser revertida em prol dos proprietários de terras.

Metodologicamente, embora a constatação do problema derive de uma situação concreta e específica no mundo, a pesquisa é marcadamente dedutiva, partindo de considerações mais gerais e abstratas para especificar e construir um direito à terra como direito da personalidade e, a partir daí, voltar os olhares para a realidade concreta no intuito de resolver o conflito. A pesquisa é exploratória, baseada em dados secundários e se vale dos procedimentos bibliográfico e documental.

O trabalho está dividido em cinco partes. Além desta introdução e da conclusão, é proposto de início um modelo de compreensão dos direitos da personalidade que contemple os dois pontos de vista clássicos (seção 2); munido desse modelo, empreende-se a aproximação do direito à terra como um direito à identidade pessoal do indígena (seção 3); por fim, confrontando o direito à terra como direito da personalidade com o direito de propriedade, é proposta uma solução normativa para a antinomia (seção 4).

\subsection{ENTRE O JUSNATURALISMO E O POSITIVISMO JURÍDICO: UMA TENTATIVA DE CONCILIAÇÃO NOS DIREITOS DA PERSONALIDADE}

Clássica celeuma na ciência do direito discute a existência de direitos sob dois paradigmas contrapostos: de um lado, os que entendem que o fenômeno do direito, enquanto exigência de juridicidade como equilíbrio, independe de experiência que estabeleça a existência de tal exigência; de outro lado, os que entendem que o fenômeno do direito é essencialmente uma realidade empírica, 
oriunda de convenções que põem o dever jurídico condicionado à imposição de uma sanção. Assim, tem-se, grosso modo, as correntes jusnaturalista e do positivismo jurídico, respectivamente.

A discussão alcança especialmente os direitos da personalidade. Aliás, há uma relação umbilical dos direitos da personalidade no debate entre as duas correntes de pensamento. Veja-se, exemplificativamente, a reclamação de Antígona, logo nas primeiras páginas do escrito de Sófocles, em relação ao direito de enterrar os mortos de acordo com os costumes, tolhido a um de seus irmãos pelo rei Creonte ${ }^{09}$. No fundo, trata-se de um ou mesmo dois direitos da personalidade: não do direito do morto de ser enterrado, mas de direitos reflexos de Antígona, realizados pelo respeito ao corpo pelo direito ao sepulcro e à reputação de seu irmão Polinice pela tutela do direito à honra.

Mais especificamente no âmbito do estudo dos direitos da personalidade no Brasil, dois autores clássicos destacam-se em cada uma dessas correntes. Sob o ponto de vista jusnaturalista, Carlos Alberto Bittar ${ }^{10}$ argumenta:

Entendemos que os direitos da personalidade constituem direitos inatos - como a maioria dos escritores ora atesta -, cabendo ao Estado apenas reconhecê-los e sancioná-los em um ou outro plano do direito positivo - em nível constitucional ou em nível de legislação ordinária -, e, dotando-os de proteção própria, conforme o tipo de relacionamento a que se volte, a saber: contra o arbítrio do poder público ou as incursões de particulares.

[...]

Isso não importa, no entanto, em cingir os direitos da personalidade aos reconhecidos pelo ordenamento jurídico. Esses direitos - muitos dos quais não configuram ou não são suscetíveis de configurar 'liberdades públicas' - existem antes e independentemente do direito positivo, como inerentes ao próprio homem, considerado em si e em suas manifestações.

Em outras palavras, a tese jusnaturalista dos direitos da personalidade defende a qualidade de direitos inatos pré-positivos e, portanto, pré-estatais. Seriam parte do plexo de direitos do homem pré-existentes à sociabilidade, e o Estado viria a conferir-lhes uma proteção especial.

Já do ponto de vista do positivismo jurídico, merece menção Adriano De

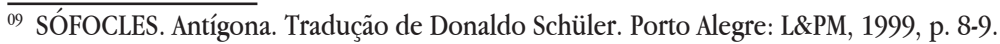

${ }^{10}$ BITTAR, Carlos Alberto. Os direitos da personalidade. Atualização de Carlos Alberto Bianca Bittar. 7. ed. Rio de Janeiro: Forense Universitária, 2004, p. 7-8.
} 
Cupis $^{11}$, jurista italiano que viveu até a primeira metade do século $\mathrm{XX}$, mas cujo pensamento teve especial repercussão no Brasil. Criticando o ponto de vista dos direitos da personalidade como direitos essenciais, rebate:

Todo o meio social tem uma sensibilidade particular relativamente à essencialidade dos direitos. É assim que, mudando a consciência moral, modificando-se o modo de encarar a posição do indivíduo no seio da sociedade, muda correlativamente o âmbito dos direitos tidos como essenciais à personalidade. Ao repercutir-se esta concepção sobre 0 ordenamento jurídico, os direitos da personalidade adquirem uma figura positiva. É só então que o atributo da essencialidade adquire um valor jurídico positivo integral, isto é, quando os direitos se revestem da referida essencialidade, não só tomam o lugar próprio no sistema do ordenamento positivo, mas adquirem, além disso, uma disciplina adequada e apta a assegurar-lhes proeminência relativamente a todos os outros direitos da pessoa a que se referem. Por tal razão, os direitos da personalidade estão vinculados ao ordenamento positivo tanto como os outros direitos subjetivos, uma vez admitido que as idéias dominantes no meio social sejam revestidas de uma particular força de pressão sobre o próprio ordenamento. Por conseqüência, não é possível denominar os direitos da personalidade como 'direitos inatos', entendidos no sentido de direitos relativos, por natureza, à pessoa.

Veja-se que, coerentemente com um determinado ponto de vista do positivismo jurídico, o argumento acima estabelece como fundamento a existência de um relativismo moral nas sociedades, que pode, em lugares e em momentos diferentes, demonstrar por meio do ordenamento jurídico os aspectos do ser humano a serem considerados como atributos da personalidade, assim juridicamente construída. Não haveria, assim, espaço para direitos inatos. Deve-se, assim, diferençar as origens dos direitos da personalidade a partir de seus fundamentos, e não em virtude de suas características ${ }^{12}$, que são senão consequências derivadas.

A despeito da divergência, defende-se a possibilidade de aproximação entre as concepções. Não se trata propriamente duma solução intermediária, com superação das anteriores, como a introdução dos valores pelo direito positivo

${ }^{11}$ DE CUPIS, Adriano. Os direitos da personalidade. Tradução de Afonso Celso Furtado Rezende. Campinas: Romana Jurídica, 2004, p. 24-25.

12 WEINERT, Iduna E. O direito da personalidade como direito natural geral: corrente naturalista clássica. Revista de Informação Legislativa, Brasília, DF, ano 27, n. 108, p. 221-228, out./dez. 1990, esp. p. 223. 
estatal, mas pelo reconhecimento da permanente tensão entre os pontos de vista. Essa tensão tem como propósito permitir o respeito a cada um dos aspectos, reconhecendo os espaços em que atuam com maior ou menor influência.

Duas premissas são básicas para o estabelecimento do diálogo.

A primeira delas é o de que há mais do direito positivo do que a lei pode propor. Enquanto o direito positivo implica o conhecimento daquilo que está colocado nas relações sociais, sejam elas formais ou informais, a lei é a manifestação mais solene da segurança jurídica. Embora o ideal seja que juridicidade e segurança jurídica andem lado a lado, esta acontece em graus. A lei, antes de promover mudanças na realidade, tem por propósito precípuo a estabilização de expectativas adquiridas pela experiência social, por meio de um documento formal que expresse tais expectativas.

Esse entendimento já se encontra presente na teoria de Santi Romano ${ }^{13}$, que analisa o fenômeno jurídico sob o ponto de vista do que denomina de instituições, como conjunto de relações jurídicas orgânicas que a compõem, formando um ordenamento jurídico próprio a consubstanciar uma ordem social que, embora limitada, não se confunde com o direito estatal. Tais instituições produzem direito, sem prejuízo de a intervenção estatal por meio da lei vir a produzir efeitos secundários, como a produção de garantias adicionais, condicionadas à existência de aparato fiscalizatório e sancionatório. Da mesma forma, outras correntes positivistas consagram formas diferentes de ver o direito sem necessariamente passar pelo culto à norma legal. É o caso, por exemplo, do realismo escandinavo em Alf Ross ${ }^{14}$, que considera o ordenamento jurídico como o "conjunto de normas que efetivamente operam na mente do juiz, porque ele as sente como socialmente obrigatórias e por isso as acata".

Tal premissa, no âmbito dos direitos da personalidade, também é constatada em Carlos Alberto Bittar ${ }^{15}$, quando inclui, além da lei, que seria a forma mais importante de expressão da norma positiva, o costume e a jurisprudência.

E a segunda delas guarda pertinência com a identificação de um espaço jurídico de deliberação normativa mesmo diante de previsões em regras legais positivadas. Mesmo quando a lei determina certa conduta para uma situação dada,

\footnotetext{
${ }^{13}$ ROMANO, Santi. O ordenamento jurídico. Tradução de Arno Dal Ri Júnior. Florianópolis: Boiteux, 2008, esp. p. 106-109.

${ }^{14}$ ROSS, Alf. Direito e justiça. Tradução de Edson Bini. Bauru, SP: Edipro, 2000, p. 59.

${ }^{15}$ BITTAR, 2004, p. 8.
} 
há controvérsias acerca do alcance dos conceitos utilizados e, diante de situações não claramente definidas, pode-se adotar uma postura de inclusão ou de exclusão.

Nesse sentido, Herbert Hart ${ }^{16}$ vai denunciar a inexorável textura aberta dos textos normativos, o que conduz ao reconhecimento, entre uma zona claramente inserida na regra jurídica e uma zona definitivamente excluída da regra jurídica, uma zona de penumbra que conduz a um dilema relativo à inclusão de determinada parcela da realidade social dentro do âmbito de proteção normativo. Dilema cuja solução fica a cargo do exercício da discricionariedade pelo julgador. Noutro plano, pode-se inserir o ponto de vista sobre a incompletude do ordenamento jurídico, na lição de Norberto Bobbio ${ }^{17}$, segundo o qual, diante de uma lacuna normativa, na verdade se está perante uma antinomia entre a norma geral que pede a exclusão do caso à aplicação da regra - a norma geral exclusiva - e a regra de aplicação da analogia, ampliando o alcance da regra para um caso por ela não previsto - a norma geral inclusiva. A antinomia então deve ser resolvida pelo intérprete segundo um critério externo.

Essa premissa implica que, com o reconhecimento da personalidade, em sentido jurídico-positivo, resta consagrado um espaço indeterminável de juridicidade, dada a textura aberta conferida à própria compreensão do que é personalidade, não apenas em sentido sintático, mas também no nível pragmático. De Cupis ${ }^{18}$ concorda com essa concepção, na medida em que sustenta ser suficiente o pressuposto da personalidade, conferida aos indivíduos pelo ordenamento jurídico, para atribuirlhes direitos subjetivos e que, em razão desse mesmo fato, seriam tidos por inatos.

Contemplando as duas premissas, pode-se construir uma aproximaçãotensão entre as teses jusnaturalista e positivista jurídica dos direitos da personalidade, a partir da consideração de que, a despeito de certos aspectos da personalidade não terem recebido a devida atenção pelo legislador, não sendo expressamente considerados como direitos da personalidade, isso não significa que esses aspectos já não estejam colocados no substrato social - nesse sentido e em certa medida, naturalizados. A tese a ser sustentada é a de que, dentro da própria riqueza das relações sociais, que são influenciadas pela tradição, ao tempo em que a reproduzem ou a modificam, certas questões relativas à juridicidade, especialmente no âmbito

\footnotetext{
${ }^{16}$ HART, H. L. A. O conceito de direito. 3. ed.Tradução de A. Ribeiro Mendes. Lisboa: Calouste Gulbenkian, 2001, esp. cap. VII, p. 137 e ss.

${ }^{17}$ BOBBIO, Norberto. Teoria do ordenamento jurídico. 10. ed. Tradução de Maria Celeste Cordeiro Leite dos Santos. Brasília, DF: UnB, 1999, p. 132-139.

${ }^{18}$ DE CUPIS, op cit., 2004, p. 26-27.
} 
da personalidade, ainda não foram adequadamente tematizadas pela razão, ou seja, ainda não teriam emergido como problemas jurídicos individualizados. $\mathrm{O}$ que aparentemente seriam novos direitos revelados ${ }^{19}$, na verdade, são direitos já existentes, porém ainda não identificados em virtude da ausência de consciência e racionalização do tema.

Noutro giro, a existência jurídica dos espectros da personalidade já se encontraria socialmente positivada mediante processos informais e complexos, porém de forma não problematizada. Tal problematização poderia vir a acontecer por meio da formação dos costumes, da emergência de conflitos pontuais ou de equivalentes funcionais que desvelariam para o sistema jurídico uma perspectiva da personalidade por ela até então ignorada. Aliás, o ordenamento jurídico já previa a proteção desses espectros da personalidade sob o ponto de vista diferenciado de outros ramos do direito, como o penal ou o constitucional ${ }^{20}$.

Assim entendida a tensão, e diante da questão acerca da consideração de novos aspectos da personalidade até então ignorados pelo texto legal, indubitável a conclusão segundo a qual deve prevalecer, como presunção geral, a inclusão deles no mesmo âmbito de proteção, inclusive pelo recurso à analogia. O Código Civil de $2002^{21}$, conquanto tenha sido tímido na disciplina dos direitos da personalidade, tratou nos arts. 11 e 12 acerca de proteções gerais a esses direitos:

Art. 11. Com exceção dos casos previstos em lei, os direitos da personalidade são intransmissíveis e irrenunciáveis, não podendo o seu exercício sofrer limitação voluntária.

Art. 12. Pode-se exigir que cesse a ameaça, ou a lesão, a direito da personalidade, e reclamar perdas e danos, sem prejuízo de outras sanções previstas em lei.

Parágrafo único. Em se tratando de morto, terá legitimação para requerer a medida prevista neste artigo o cônjuge sobrevivente, ou qualquer parente em linha reta, ou colateral até o quarto grau.

Embora passível de encômios pela inovação legislativa no tema, o Código

\footnotetext{
${ }^{19}$ WEINERT, op cit., 1990, p. 228.

${ }^{20}$ MORATO, Antonio Carlos. Quadro geral dos direitos da personalidade. Revista da Faculdade de Direito da Universidade de São Paulo, São Paulo, v; 106/107, p. 121-158, jan./dez. 2011/2012.

${ }^{21}$ BRASIL. Lei no 10.406, de 10 de janeiro de 2002. Institui o Código Civil. Brasília, DF: Presidência da República, 2002. Disponível em: <http://www.planalto.gov.br/ > . Acesso em: 15 ago. 2016.
} 
Civil é alvo de duras críticas quanto ao seu conteúdo ${ }^{22}$. O art. 11 lida com "os direitos da personalidade", sem dizer explicitamente que somente seriam direitos da personalidade aqueles expressamente previstos no código - diversamente do tratamento dado aos contratos atípicos (art. 425), aos títulos de crédito (art. 903), às hipóteses de perda da propriedade (art. 1.275) ou aos testamentos especiais (art. 1.887). Especialmente para os limites desta pesquisa, o art. 12 acima citado, equivalente ao art. $70, \mathrm{n}^{\mathrm{O}} 1$, do Código Civil português, consubstancia os dois meios de tutela da personalidade, na lição de Pedro Pais de Vasconcelos ${ }^{23}$ : "as providências especiais de defesa da personalidade e a responsabilidade civil".

\section{DIREITO À TERRA COMO UM DIREITO À IDENTIDADE DO INDÍGENA}

Em seguimento, busca-se investigar se o direito a terra revelar-se-ia como um caso especialíssimo de direito à identidade, exclusivo para o indígena. Assim, cabem algumas ponderações em torno especificamente da repercussão dos direitos da personalidade sobre a identidade para se verificar se realmente é sustentável a posição de que seria este um fundamento jurídico para a tutela do silvícola.

A seção é dividida em duas partes: na primeira, apresenta-se o referencial teórico geral sobre o direito à identidade, analisando-se as diversas maneiras de sua manifestação; na segunda, adentra-se especificamente à relação do indígena com sua terra e de como isso pode ser entendido como um direito à identidade.

\subsection{O DIREITO À IDENTIDADE COMO DIREITO DA PERSONALIDADE E SEUS ESPECTROS DE REALIZAÇÃO}

Com efeito, o direito à identidade por si só já enfrenta dificuldades iniciais por não possuir previsão expressa no Código Civil. Sobre esse direito, Bittar ${ }^{24}$ observa que ele "inaugura o elenco dos direitos de cunho moral, exatamente porque se constitui no elo de ligação entre o indivíduo e a sociedade em geral". Na verdade, o direito à identidade acaba sendo percebido por meio de seus diversos espectros de realização.

\footnotetext{
$\overline{22}$ SCHREIBER, Anderson. Direitos da personalidade. 2. ed. São Paulo: Atlas, 2013, p. 12.

${ }^{23}$ VASCONCELOS, Pedro Pais de. Direito de personalidade. Coimbra: Almedina, 2006, p. 126.

${ }^{24}$ BITTAR, op cit., 2004, p. 128.
} 
Um primeiro desses espectros do direito à identidade é revelado por um ponto de vista estritamente individualista, que possibilita distinguir indubitavelmente uma pessoa de todas as demais ${ }^{25}$. Como salienta De Cupis ${ }^{26}$ :

$\mathrm{O}$ indivíduo, como unidade da vida social e jurídica, tem necessidade de afirmar a própria individualidade, distinguindose dos outros indivíduos, e, por consequência, ser conhecido por quem é na realidade. $O$ bem que satisfaz esta necessidade é o da identidade, o qual consiste, precisamente, no distinguirse das outras pessoas nas relações sociais.

Assim, quando se cuida do direito à identidade pode-se estar falando na necessidade de afirmação da própria individualidade, por um conjunto de qualificativos e indicadores que permitem a singularização do indivíduo em meio às diversas personas existentes na sociedade. Nessa perspectiva, vêm-se desenvolvendo variadas espécies de direito à identidade, que vão além da mera tutela do nome e sobrenome, pseudônimo ou apelido ${ }^{27}$ - o nome é um dos direitos tutelados pelo Código Civil, nos arts. 16 a 19 -, alcançando inclusive, a partir de um direito de ser a si mesmo ${ }^{28}$, o direito à imagem e o direito à voz, ambos na medida em que se prestam à individualização da pessoa - há certas nuanças relacionadas à imagem e à voz que não dizem respeito necessariamente à identidade. Para Bittar ${ }^{29}$, ainda tratando do direito à identidade pessoal:

Nesse sentido, aliás, a imagem e a voz também cumprem, a par de outros caracteres pessoais, a missão exposta, sob âmbito mais restrito, exigindo a prévia fixação e maior esforço associativo; mas, de qualquer sorte, nesse passo, atestam a contínua interpenetração dos direitos da personalidade já referida.

No mesmo sentido, arrematando as ponderações acima, confiram-se as palavras de Anderson Schreiber ${ }^{30}$ :

\footnotetext{
${ }^{25}$ FERNÁNDEZ SESSAREGO, Carlos. Daño a la identidad personal. Themis: Revista de Derecho, Lima, n. 36, p. 245-272, jun./dez. 1997, p. 248.

${ }^{26}$ DE CUPIS, op cit., 2004, p. 179.

${ }^{27}$ SCHREIBER, op cit., 2013, p. 187 e ss.

${ }^{28}$ SCHREIBER, op cit., 2013, p. 211.

${ }^{29}$ BITTAR, op cit., 2004, p. 128.

${ }^{30}$ SCHREIBER, op cit., 2013, p. 216.
} 
Como se viu, o direito à identidade pessoal vai muito além da proteção ao nome. Abrange traços distintivos da mais variada ordem, como estado civil, etnia, orientação sexual, impressões digitais, ideologia política, crença religiosa e assim por diante. Não há aqui, a rigor, sobreposição com aspectos já abrangidos por outros direitos da personalidade, como o direito à imagem e o direito à privacidade. Isso porque o direito à identidade pessoal não se confunde com a tutela isolada e estática de cada um desses aspectos. A identidade pessoa deve ser vista em perspectiva funcional e dinâmica, voltada a promover e garantir uma fidedigna apresentação da pessoa humana, em sua inimitável singularidade.

Pode-se agregar ainda a essa perspectiva do direito à identidade uma proteção à verdade pessoal ${ }^{31}$, de modo a conferir à pessoa humana uma proteção "contra $[. .$.$] atos que a coloquem, na eloquente expressão italiana, sotto falsa luce$ (sob falsa luz), apresentando-a de modo errôneo no meio social" ${ }^{2}$. Ao sistema jurídico cabe oferecer mecanismos que lhe permitam corrigir eventuais informações falsas relativas à sua identidade, inclusive no que tange a uma identidade ideológica ou até mesmo uma identidade científica ${ }^{33}$ - embora tais aspectos possam repercutir mais sobre o plano da honra subjetiva, resta um interesse individual em não ver seu nome associado a certas ideias ${ }^{34}$-, manifestando-se por meio de instrumentos processuais como o habeas data.

Mas esse ponto de vista identitário não é suficiente. Um segundo espectro do direito à identidade consiste no respaldo à necessidade de o indivíduo conhecer a si próprio, de investigar sua historicidade pessoal ${ }^{35}$. Aqui, a preocupação não está na afirmação da própria individualidade, mas na busca de meios que permitam ao sujeito localizar-se moralmente no mundo, ressignificando sua existência. Nessa acepção insere-se o direito à investigação de paternidade e maternidade (art. 1.615 do Código Civil), o direito à identificação genética e ao conhecimento das origens

\footnotetext{
${ }^{31}$ FERNÁNDEZ SESSAREGO, op cit., 1997, p. 249-250.

${ }^{32}$ SCHREIBER, op cit., 2013, p. 211.

${ }^{33}$ FERNÁNDEZ SESSAREGO, op cit., 1997, p. 262-265.

${ }^{34}$ SCHREIBER, op cit., 2013, p. 211.

${ }^{35}$ REIS, Rafael Luís Vale e. O direito ao conhecimento das origens genéticas. Coimbra: Coimbra, 2008, p. 58-62.
} 
biológicas (art. 48 do Estatuto da Criança e do Adolescente, recentemente inserido pela lei $\left.\mathrm{n}^{\mathrm{o}} 12.010 / 2009\right)$.

Para os pesquisadores na área, o direito à identidade poderia muito bem resumir-se a essas duas perspectivas. Carlos Fernández Sessarego ${ }^{36}$ identifica esses dois espectros da identidade como dois componentes: um componente biológico, de caráter estático, e um componente cultural, de caráter dinâmico. A identidade de um indivíduo se constituiria pela conjunção unitária de elementos estáticos e dinâmicos. Entretanto, aceitando-se o caráter aberto dos direitos da personalidade, possibilitando sua expansão $0^{37}$, faz-se necessário ampliar os horizontes do direito à identidade.

Nesse sentido, um terceiro espectro do direito à identidade pode levar em conta uma relação dialética que se estabelece entre a pessoa e os componentes da identidade, dessa vez sob o ponto de vista da sociedade. Em outras palavras, na medida em que o critério de identificação singulariza a pessoa, ele ao mesmo tempo cria um vínculo entre essa pessoa e a sociedade, passando aquela a ser reconhecida em virtude do qualificativo e, portanto, como pertencente a um grupo dentro dessa sociedade. Isso acontece de modo mais claro com a questão patronímica: o sobrenome, ao mesmo tempo em que individualiza um sujeito, também permite identificá-lo como membro pertencente de uma determinada família.

Particularmente em relação à terra, Haesbaert ${ }^{38}$ estipula a existência de duas dimensões que recaem sobre a territorialidade: uma dimensão funcional, entendida a terra como recurso e valor de troca, e uma dimensão simbólica, entendida a terra como símbolo, do qual permite-se extrair identidades.

Assim, as sociedades tradicionais conjugavam a construção material ('funcional') do território como abrigo e base de 'recursos' com uma profunda identificação que recheava o espaço de referentes simbólicos fundamentais à manutenção de sua cultura. Já na sociedade 'disciplinar' moderna (até por volta do século XIX) vigorava a funcionalidade de um 'enclausuramento disciplinar' individualizante através do

\footnotetext{
${ }^{36}$ FERNÁNDEZ SESSAREGO, op cit., 1997, p. 248.

${ }^{37}$ SCHREIBER, op cit., 2013, p. 217.

${ }^{38}$ Haesbaert, op. cit., 2008, p. 22-23.
} 
espaço - não dissociada, é claro, da construção da identidade (individual, mais do que de grupo). Mais recentemente, nas sociedades 'de controle' ou 'pós-modernas' vigora o controle da mobilidade, dos fluxos (redes) e, conseqüentemente, das conexões - o território passa então, gradativamente, de um território mais 'zonal' ou de controle de áreas para um 'território-rede' ou de controle de redes. Aí, o movimento ou a mobilidade passa a ser um elemento fundamental na construção do território.

Poder-se-ia contra-argumentar no sentido de que não se trataria aqui de um direito à identidade pessoal, mas na verdade de um aspecto mais relacionado à identidade social. Ora, a identidade pessoal pode funcionar socialmente, num esquema de teoria dos conjuntos, sendo a pessoa identificada por ser integrante de qualquer um deles e individualizada pela concorrência de todos eles. Portanto, a identidade pessoal pode funcionar em níveis, havendo impactos na construção da individualidade. Há subjacente à discussão uma questão intrínseca ao ser humano que é o sentimento de pertencimento (identificação) a um determinado grupo, cuja frustração pode levar à perda da própria referência identitária enquanto sujeito inserido numa sociedade.

\subsection{O DIREITO À TERRA COMO UM ELEMENTO IDENTITÁRIO INDÍGENA}

No caso do indígena, há peculiaridades que merecem a atenção devida. Em primeiro lugar, é questionável se o indígena de fato possui uma compreensão de identidade pessoal. A cosmovisão dos povos indígenas é muito mais ligada a uma vida comunitária e, assim, a uma identidade coletiva - ou seja, há uma sobreposição do coletivo em detrimento de cada um dos membros individualmente considerados, mas há também a compreensão de que cada indivíduo tem um papel fundamental na comunidade. Para Dantas ${ }^{39}$,

As sociedades tradicionais, também denominadas de holísticas, constituem enquanto um todo em seu modo de ser. A pessoa, nessas sociedades, é construída pela cultura, em ralação complementária com seu contexto social. Distancia-se, portanto, da noção moderna de indivíduo como ser isolado, com verdade interior.

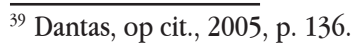


Surge aqui um conflito decorrente do multiculturalismo e do risco de se estar realizando um colonialismo ideológico. Do ponto de vista do indígena, ele não teria originariamente uma compreensão de individualismo, base fundamental do pensamento civilizatório moderno de raízes indo-europeias, do qual derivam tanto os direitos humanos quanto os direitos da personalidade. Nesse sentido, ainda sob o ponto de vista do indígena em suas bases comunitárias, talvez seja um contrassenso falar em defesa de direitos de uma identidade pessoal cuja existência ele próprio não reconheceria. O estabelecimento desse direito à identidade do indígena pode, portanto, configurar uma imposição da racionalidade do homem branco sobre a cosmovisão indígena, e daí o colonialismo ideológico. Partindo apenas desse ponto de vista, deve-se concluir com Dantas ${ }^{40}$ que

[...] a categoria abstrata, genérica, unívoca e isolada de sujeito da modernidade não serve de paradigma para definir o sujeito coletivo em que se constituem as sociedades e pessoas indígenas. É necessário um novo paradigma, possivelmente aberto, que possibilite um espectro de contextualização tão plural e concreto, quanto diverso e real é o panorama da sociedade brasileira.

Mas talvez não seja apenas sob tal perspectiva que se devam solucionar os problemas jurídicos dos indígenas, haja vista que deve-se buscar soluções eficazes com a disciplina normativa atual. Por outro lado, não se pode negar, desde um ponto de vista civilizatório, que, independentemente da efetiva compreensão e da existência de reconhecimento do índio acerca de sua identidade pessoal e de um direito a ela, haveria inegavelmente a existência de uma individualidade construída no inconsciente, razão por que o próprio indígena não a identifique ou reconheça. Nesse sentido, justificam-se os suicídios em virtude da perda de perspectiva, consubstanciando uma crise de autorreferência no mundo. Os espectros da identidade podem se manifestar mesmo sem a autoconsciência deles.

Quanto a esse problema multicultural, embora o índio possa não aceitar que seja um indivíduo e que possua direitos da personalidade, a sociedade civilizada tem plena capacidade de utilização de seus institutos próprios, derivadas de sua cosmovisão do mundo, de modo a estabelecer a conduta precautória devida para atuação do Estado e para identificar expectativas legítimas por parte dos cidadãos

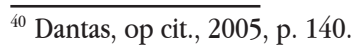


que intentam ocupar terras possivelmente tradicionais indígenas. Essa utilização legitima-se, todavia, quando o manejo dos institutos de fato se presta em favor dos povos indígenas, e não em proveito próprio do homem civilizado, com o único intuito de criar um discurso legitimador de sua atitude exploratória.

Deve-se levar em conta que, em virtude da colonização das Américas pelo homem moderno, branco e europeu, há duas tradições bem claras: os colonizadores não possuem um laço originário com a terra e chegam com o propósito de ocupá-la para fins econômicos; os índios, por sua vez, possuem um forte laço sentimental com a terra, chegando a ser identificado um vínculo espiritual sagrado. A mãe-terra é quem dá ao índio todos os meios para que ele tenha uma vida boa. Os índios vivem uma relação simbiótica com a terra originária, sendo inclusive o local onde são sepultados seus antepassados com o objetivo de cultuá-los. Para a tradição de colonização, a relação do homem com a terra se dá por meio de uma objetificação, mediante o estabelecimento de título real com o intuito de exploração dos recursos naturais para fins econômicos; para a tradição autóctone e comunitária, a relação do homem com a terra se dá por um caminho marcadamente subjetivista, mediante esquemas pré-modernos.

No que concerne aos índios guaranis, dos quais os Kaiowá são um subgrupo, existe em sua cosmovisão o mito da "terra do sem mal", uma terra prometida que a comunidade deveria encontrar, razão pela qual são comumente vistos como nômades. Entretanto, não é bem assim o que se passa na cosmovisão deles mesmos.

Para um Guarani é absolutamente incognoscível a idéia de fronteira. Eles não se dizem gaúchos, catarinas, paranaenses, paulistas, capixabas, mato-grossenses, uruguaios ou bolivianos. São Guarani e circulam por Ywy Rupa, como eles denominam o território Guarani. [...] Ywy rupa é, então, o mundo no qual se encontram as aldeias atuais, os caminhos percorridos e os lugares ocupados pelos antepassados, onde estão as áreas sonhadas, os espaços temporariamente desocupados e os locais a serem ainda apropriados. Compreender isso é entender a alma Guarani ${ }^{41}$.

Como ressalta Bittencourt" ${ }^{42}$, "[e]ntretanto, no momento, apesar das nãofronteiras, os guaranis concentram-se em ter um lugar para que possam viver, 
mantendo sua tradição, religião, leis, cultura, comportamento e costumes".

Importa retomar as ponderações feitas acerca do debate entre jusnaturalismo e positivismo jurídico no âmbito dos direitos da personalidade (seção 1): embora não haja previsão expressa na legislação acerca dessa modalidade, deve-se investigar em sistemas informais não estatais, como os costumes, especialmente para o problema ora apresentado, a presença da positividade jurídica da relação jurídica do homem consigo próprio. No caso do indígena, a despeito de a relação com a terra ser dotada de um forte viés teológico - a terra muitas vezes é reconhecida como uma deidade -, o que dificulta ainda mais o reconhecimento da normatividade jurídica, há inegavelmente um aspecto moral que estabelece um liame do indígena com a terra, um liame equivalente ao vínculo que o índio estabelece com sua família.

Se o patronímico é um elemento que inegavelmente se constitui como direito da personalidade, por permitir a identificação do indivíduo, ao mesmo tempo também possibilita que o indivíduo se identifique e seja identificado com a família à qual o patronímico diz respeito. Por analogia, se o contato com a terra originária permite ao indivíduo que este se identifique enquanto indígena pertencente a uma tribo, historicamente construída nessa terra, e que ele seja identificado como pertencente a uma comunidade indígena em virtude de sua localização geográfica, há que se reconhecer que o vínculo do índio com a terra originária é um elemento identitário e, portanto, o direito à terra deve ser entendido como um direito à identidade do indígena.

O reconhecimento de normas costumeiras pelas vias estatais deve passar pela manifestação pelo judiciário, como chancela formal de identificação da manifestação positivista. Nesse sentido, na própria decisão do Supremo Tribunal Federal no Caso Raposa Serra do Sol ${ }^{43}$, mencionado na introdução, o acórdão aponta que o art. 231 da Constituição, ao garantir os direitos originários às terras tradicionalmente ocupadas, possui como propósito último, dentro do marco do constitucionalismo fraternal e do reconhecimento de uma dívida histórica, salvaguardar "os índios a desfrutar de um espaço fundiário que lhes assegure meios dignos de subsistência econômica para mais eficazmente poderem preservar sua identidade somática, linguística e cultural" [grifos nossos]. Logo, há, no fenômeno da relação social do indígena com a terra originalmente ocupada por sua tribo, um aspecto que possui efeitos especificamente jurídicos, que atinge foros de direito civil, como um direito

\footnotetext{
$\overline{43}$ BRASIL, 2009, online.
} 
da personalidade do ponto de vista identitário.

\section{O CONFLITO ENTRE O DIREITO À TERRA COMO DIREITO DA PERSONALIDADE E O DIREITO À PROPRIEDADE COMO DIREITO REAL}

Superada a discussão em torno da existência de um direito da personalidade subjacente à relação do índio com sua terra, cabe nesta derradeira seção examinar e propor uma solução para a antinomia existente, no âmbito do direito civil, entre o direito à terra como um direito da personalidade indígena e o direito à terra como um direito real para o homem civilizado.

Oportuno fazer a ressalva de que não se deve confundir a órbita civil com a constitucional. No âmbito constitucional, há direitos igualmente equivalentes também em conflito normativo.

De um lado, a Constituição de $1988^{44}$ protege a propriedade privada tanto na forma de uma garantia fundamental (art. $5^{\circ}$, XXII) como na necessária consideração pelo Estado na formulação de políticas econômicas, alçado ao status de princípio da Ordem Econômica (art. 170, II). Especificamente para as propriedades rurais, a despeito de restrições constitucionais ao cumprimento da denominada função social (art. 5० XXIII; art. 170, III), que conduzem a repercussões na seara tributária - pelo desestímulo a propriedades improdutivas e a proteção ao minifúndio (art. $153, \S 4^{0}$, I e II) - e na política agrária - desapropriação para fins de reforma agrária, ressalvadas a pequena e média propriedades e a propriedade produtiva (art. 185) -, a Constituição confere uma série de proteções contra a intervenção estatal, ainda no capítulo dos direitos fundamentais, como no caso da desapropriação prévia, justa e em dinheiro (art. $5^{\circ}$, XXIV).

De outro, a mesma Constituição confere aos indígenas os direitos originários às terras tradicionalmente ocupadas (art. 231), sendo considerados possuidores permanentes (art. $231, \S 2^{\circ}$ ), enquanto a União fica como detentora do título de propriedade dessas terras (art. 20, XI). Além disso, o texto constitucional elucida que as terras são inalienáveis e indisponíveis e os direitos indígenas são imprescritíveis, somente podendo os índios ser removidos em situações excepcionais de risco (art. $\left.231, \S 4^{\mathrm{o}}\right)$.

$\overline{44}$ BRASIL, 1988, online. 
A antinomia existente na Constituição entre os interesses em questão já foi resolvida pelo Supremo Tribunal Federal ${ }^{45}$, no julgamento do Caso Raposa Serra do Sol. Quando constatado, mediante laudos antropológicos, que se trata de área tradicionalmente ocupada por tribos indígenas quando da promulgação da Constituição de 1988 com o intuito de perdurabilidade, deve-se aplicar o teor do art. $231, \S 6^{\circ}$, para declarar a nulidade e extinção dos atos de ocupação, domínio, posse e exploração das terras objeto da disputa, sem qualquer direito à indenização.

No caso das tribos Guarani-Kaiowá, na região do Mato Grosso do Sul, a situação parece ser um tanto diferente. Argumenta-se, pela versão civilizatória do conflito $^{46}$, que os títulos de propriedade datam de várias gerações e que a queixa indígena seria, assim, mero dissabor. O Judiciário, por sua vez, já teria chancelado esse entendimento, ao determinar o despejo de grupo indígena, mas o impasse político e social permanece na região ${ }^{47}$. Não haveria aí, a princípio, uma solução do ponto de vista constitucional - salvo se houvesse o revolvimento de fatos, como a produção de novo estudo antropológico com o propósito de contestação ao original, mas isso por si só já enfrentaria juridicamente outros problemas com a autoridade da coisa julgada e o respeito ao devido processo legal.

$\mathrm{O}$ direito civil pode fornecer uma releitura da questão, e tentar resolver o impasse, à vista dos suicídios registrados ${ }^{48}$. No entanto, a discussão não pode levar em consideração a existência de má-fé por nenhuma das partes. Então se deve assumir que há, de um lado, um título de propriedade legítimo pelos produtores rurais e, de outro, um direito a terra, compreendido aqui como um direito da personalidade. $\mathrm{Na}$ órbita do Código $\mathrm{Civil}^{49}$, ainda de maneira geral, vale recordar que as violações a direitos com danos, ainda que morais, implicam o cometimento de ato ilícito (art. 186), ficando o agente que deu causa obrigado à reparação do dano (art. 927).

Assim, reconhecer que existe um direito da personalidade indígena no trato do direito à terra por ele tradicionalmente ocupada, a despeito das limitações constitucionais relativas ao direito indígena, especialmente quando essa terra tenha formalmente deixado de ser ocupada em período pretérito à Constituição de 1988 e reconhecido pelo Judiciário, poderia importar na aplicação do art. 12 do Código Civil, já mencionado anteriormente (seção 2), a saber, a exigência de cessão da lesão

\footnotetext{
45 BRASIL, op cit., 2009, online.

${ }^{46}$ UNTV, op cit., 2014, online.

${ }^{47}$ CARNEIRO, op cit., 2012, online.

${ }^{48}$ LYONS, op cit., 2015, online.

49 BRASIL, op cit., 2002, online.
} 
ao direito da personalidade, e a reclamação em perdas e danos. Quanto à primeira das tutelas, relativa às providências especiais de defesa da personalidade, cuida-se de remédios diretos, de caráter preventivo ou atenuante. Na lição de Pedro Pais de Vasconcelos ${ }^{50}$, pesa em favor dos primeiros. Deve-se, assim, entender-se que, ao decretar as providências, o juiz não deve exceder o que for suficiente e deve actuar com moderação, de modo a lesar ou perturbar o menos possível terceiros. Há que encontrar, caso a caso, um equilíbrio entre o mínimo possível de lesão ou incómodo a terceiros e a eficácia necessária. Tudo isso de acordo com o prudente arbítrio do julgador.

$\mathrm{O}$ autor entende que a cessão da lesão somente tem caráter atenuante e não repressivo, já que após a realização da ofensa a um direito da personalidade, somente é possível atenuar os efeitos da ofensa já cometida ${ }^{51}$.

Ademais, ainda segundo as regras do art. 12, a mera violação a direito da personalidade, ainda que supostamente de boa-fé, comportaria reparação de perdas e danos morais. Essa providência não possui o condão de conferir um conforto psicológico para a vítima da violação a um direito da personalidade; a indenização é incapaz, prática e juridicamente, de reparar o sofrimento e a dor provocados pela ofensa. Sob o âmbito jurídico, a indenização nada mais é do que um mecanismo de compensação por um direito violado.

No conflito em exame, eventual devolução das terras aos indígenas não desfaz a lesão cometida no passado - a ofensa já teria sido perpetrada, cabendo apenas o recurso a medidas atenuantes; por outro lado, a indenização relativa à reparação de perdas e danos também não é uma medida apropriada para compensar os direitos violados, sob o ponto de vista da cosmovisão indígena. A satisfação para os indígenas seria, de fato, garantir-se a proteção dos direitos da personalidade mediante o desfazimento dos títulos de propriedade. Dessa forma, a única tutela da personalidade possível para as comunidades indígenas da região seria tão-somente a devolução das terras tradicionalmente ocupadas pelos povos originários.

Do ponto de vista do proprietário de boa-fé, a tutela acima exposta acarretaria a perda, no todo ou em parte, de sua propriedade rural. Uma supressão de propriedade que seria realizada pelas vias judiciais. Mas o art. 186 do Código Civil não discute sobre a caracterização de má-fé, mas única e exclusivamente a atuação dolosa ou culposa que viole direito e cause dano. No caso, haveria uma violação

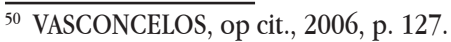

${ }^{51}$ VASCONCELOS, op cit., 2006, p. 130.
} 
ao direito de propriedade desses cidadãos, direito esse embasado em títulos por vezes antigos, transparecendo a expectativa juridicamente estabilizada. Poderia o proprietário exigir sua manutenção na propriedade, com base em título, ou, caso viesse efetivamente a perdê-la, a percepção de perdas e danos.

Entre os danos sofridos pelos indígenas e as perdas e danos do proprietário das terras, a consideração dos direitos da personalidade como intransmissíveis e irrenunciáveis, por força do art. 11 do Código Civil ${ }^{52}$, pesa em favor dos primeiros. Deve-se, além disso, buscar a interpretação que produzir menores tensões ao sistema jurídico e, portanto, os melhores resultados para a antinomia, qual seja: aos índios, a devolução das terras tradicionalmente ocupadas; aos proprietários, a reparação de perdas e danos.

Veja-se que a solução ora apontada não é condizente com as normas previstas na Constituição; mas a antinomia aqui travada é, antes de tudo, civil. Enquanto nos termos constitucionais os índios não teriam direitos às terras tradicionalmente ocupadas se já houvesse propriedade rural estabilizada anteriormente à promulgação da Constituição, o direito civil pode salvaguardar esses direitos, considerando-os como direitos da personalidade; em contrapartida, enquanto segundo as regras constitucionais o proprietário de imóvel localizado em terras tradicionalmente ocupadas não teria direito a qualquer indenização (art. $231, \S 6^{\circ}$ ), pelas proteções civis aos direitos reais teria ele direito à indenização.

Voltando-se novamente à Constituição, e considerando que a União seria, em última instância, a proprietária das terras a serem devolvidas aos indígenas para posse permanente (art. 20, XI), aplicar-se-ia, nesse sentido, a garantia de indenização justa, prévia e em dinheiro aos proprietários de boa-fé, a ser paga pela União (art. $5^{\circ}$, XXIV). Em oposição aos indígenas, os antigos proprietários, munidos da indenização justa, poderão desenvolver suas atividades em áreas equivalentes localizadas longe da zona de conflito.

\section{CONCLUSÃO}

Em arremate, a pesquisa consegue, com um grau razoável de plausibilidade, confirmar as hipóteses iniciais. Primeiramente, há, entre as diversas e multifacetadas 
perspectivas da relação do índio com a terra tradicionalmente ocupada pelos povos originários, uma que estabeleceria um liame identitário do índio enquanto indivíduo. Saturado juridicamente por vias informais, como os costumes, demonstraria o surgimento de um direito à terra como direito à identidade indígena e um próprio direito da personalidade.

Em segundo lugar, à consideração de que o direito constitucional não consegue dar uma solução pacificadora para o conflito, consegue-se, a partir da primeira conclusão, construir uma solução para a antinomia entre o direito à identidade indígena pela terra como direito da personalidade e o direito à propriedade rural como um direito real, com base numa interpretação que privilegia os direitos da personalidade. Assim, caberia aos índios o direito à posse das terras tradicionalmente ocupadas pelos povos originários e aos proprietários restaria 0 direito à indenização prévia, justa e em dinheiro.

A pesquisa realizada denuncia em favor de uma separação mais forte entre o direito constitucional e o direito civil, no âmbito das relações específicas que cada um desses ramos consegue lidar. A despeito do projeto maior de unificação do direito civil pela via constitucional, e dos estudos sobre constitucionalização das relações privadas, ainda se vê que cada ramo pode dar soluções diferentes para os problemas sociais.

A tese ora sustentada, dado o caráter vanguardista, pode ser considerada radical e de difícil concretização, porque promove uma situação mais generalizada de insegurança jurídica, já que os índios poderiam a partir de então pleitear direitos à terra originária mesmo sem respaldo constitucional. Não se está defendendo aqui um direito generalizado às terras originárias, baseada apenas em autodeclaração. É preciso que a proteção seja respaldada em estudos antropológicos sérios e comprometidos com a satisfação da dignidade dos indígenas. A decisão do Supremo Tribunal Federal no Caso Raposa Serra do Sol deve ser igualmente respeitada no que tange às circunstâncias de fato e às condições procedimentais. Além disso, o caso concreto demonstra que as tribos Guarani-Kaiowá no Estado do Mato Grosso do Sul realmente estão passando por crises relevantes de identidade. 


\section{REFERÊNCIAS}

BITTAR, Carlos Alberto. Os direitos da personalidade. Atualização de Carlos Alberto Bianca Bittar. 7. ed. Rio de Janeiro: Forense Universitária, 2004.

BITTENCOURT, Raquel Pereira. A busca do paraíso mitológico pela cultura indígena guarani e afro-americana. Linguagens: revista de letras, artes e comunicação, Blumenau, v. 2, n. 1, p. 59-68, jan./abr. 2008. Disponível em: < http://proxy.furb.br/ ojs/index.php/linguagens/article/view/974> . Acesso em: $1^{\mathrm{O}}$ jul. 2017.

BOBBIO, Norberto. Teoria do ordenamento jurídico. 10. ed. Tradução de Maria Celeste Cordeiro Leite dos Santos. Brasília, DF: UnB, 1999.

BRASIL. Constituição (1988). Constituição da República Federativa do Brasil de 1988. Brasília, DF: Assembleia Nacional Constituinte, 1988. Disponível em: < http:// www.planalto.gov.br/>. Acesso em: 15 ago. 2016.

BRASIL. Lei n $\mathbf{n}^{\mathbf{0}}$ 10.406, de 10 de janeiro de 2002. Institui o Código Civil. Brasília, DF: Presidência da República, 2002. Disponível em: < http://www.planalto.gov. br/>. Acesso em: 15 ago. 2016.

BRASIL. Supremo Tribunal Federal. Tribunal Pleno. Petição 3.388 / RR. Relator Ministro Carlos Britto. Julgado em: 19 mar. 2009. Brasília, DF: STF, 2009. Disponível em: <http://stf.jus.br/>. Acesso em: 25 ago. 2016.

CARNEIRO, Júlia Dias. Carta sobre 'morte coletiva' de índios gera comoção e incerteza. BBC Brasil, Rio de Janeiro, 24 out. 2012. Disponível em: < http://www. bbc.com/>. Acesso em: 15 ago. 2016.

DANTAS, Fernando Antonio de Carvalho. A noção de pessoa e sua ficção jurídica: a pessoa indígena no direito brasileiro. Hiléia: revista de direito ambiental da Amazônia, Manaus, n. 5, p. 121-144, jun./dez. 2005. Disponível em: < http://www. pos.uea.edu.br/data/direitoambiental/hileia/2005/5.pdf > . Acesso em: $1^{\mathrm{o}}$ jul. 2017.

DE CUPIS, Adriano. Os direitos da personalidade. Tradução de Afonso Celso Furtado Rezende. Campinas: Romana Jurídica, 2004. 
FELLET, João. Brasil é cobrado na OEA por violência contra índios. BBC Brasil, São Paulo, 20 out. 2015. Disponível em: < http://www.bbc.com/> . Acesso em: 15 ago. 2016.

FERNÁNDEZ SESSAREGO, Carlos. Daño a la identidad personal. Themis: Revista de Derecho, Lima, n. 36, p. 245-272, jun./dez. 1997. Disponível em: < http://themis. pe/>. Acesso em: 15 ago. 2016.

HAESBAERT, Rogério. Dos múltiplos territórios à multiterritorialidade. In: HEIDRICH, A. L. et al. A emergência da multiterritorialidade: a ressignificação da relação do humano com o espaço. Canoas; Porto Alegre: Ed. ULBRA; Ed. da UFRGS, 2008. p. 19-36.

HART, H. L. A. O conceito de direito. Tradução de A. Ribeiro Mendes. 3. ed. Lisboa: Calouste Gulbenkian, 2001.

LYONS, Charles. Suicides spread through a Brazilian tribe. The New York Times, New York, Sunday Review, Opinion, 2 jan. 2015. Disponível em: < http://www. nytimes.com/>. Acesso em: 15 ago. 2016.

MORATO, Antonio Carlos. Quadro geral dos direitos da personalidade. Revista da Faculdade de Direito da Universidade de São Paulo, São Paulo, v. 106/107, p. 121-158, jan./dez. 2011/2012.

REIS, Rafael Luís Vale e. O direito ao conhecimento das origens genéticas. Coimbra: Coimbra, 2008

ROMANO, Santi. O ordenamento jurídico. Tradução de Arno Dal Ri Júnior. Florianópolis: Boiteux, 2008.

ROSS, Alf. Direito e justiça. Tradução de Edson Bini. Bauru, SP: Edipro, 2000.

SCHREIBER, Anderson. Direitos da personalidade. 2. ed. São Paulo: Atlas, 2013.

SÓFOCLES. Antígona. Tradução de Donaldo Schüler. Porto Alegre: L\&PM, 1999.

TAVARES, Elaine. Ywy rupa: a territorialidade Guarani. Ciranda: internacional da comunicação compartilhada, 11 maio 2007. Disponível em: <http://ciranda.net/ 
Ywy-rupa-a-territorialidade?lang=pt_br $>$. Acesso em: $1^{0}$ jun. 2017.

UNTV. Suicide and despair among Brazil's indigenous. 21 $1^{\text {st }}$ Century Series, Programme \#97, 22 dec. 2014, 08:54. Disponível em: < http://www.unmultimedia. org/> . Acesso em: 15 ago. 2016.

VASCONCELOS, Pedro Pais de. Direito de personalidade. Coimbra: Almedina, 2006.

WEINERT, Iduna E. O direito da personalidade como direito natural geral: corrente naturalista clássica. Revista de Informação Legislativa, Braślia, DF, ano 27, n. 108, p. 221-228, out./dez. 1990.

Recebido em: 26 de janeiro de 2017 Aceito em: 01 de novembro de 2017 